\title{
Shared Decision-Making During Inpatient Rounds: Opportunities for Improvement in Patient Engagement and Communication
}

Rebecca Blankenburg, MD, MPH ${ }^{1 *}$, Joan F. Hilton, ScD, MPH², Patrick Yuan, BA³, Stephanie Rennke, MD, Brad Monash, MD,

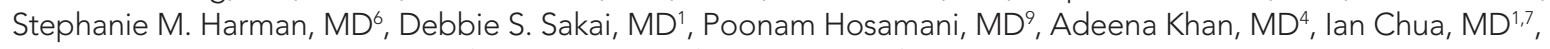
Eric Huynh, BS ${ }^{8}$, Lisa Shieh, MD', Lijia Xie, MD ${ }^{10}$, Jason M. Satterfield, PhD ${ }^{11}$

'Division of Hospital Medicine, Department of Pediatrics, School of Medicine, Stanford University, Stanford, California; ${ }^{2}$ Department of Epidemiology and Biostatistics, University of California, San Francisco, San Francisco, California; ${ }^{3}$ Department of Medicine, University of California, San Francisco, San Francisco, California; ${ }^{2}$ Division of Hospital Medicine, Department of Medicine, University of California, San Francisco, San Francisco, California; ${ }^{5}$ Division of Hospital Medicine, Department of Medicine, and Division of Hospital Medicine, Department of Pediatrics, University of California, San Francisco, San Francisco, California; ${ }^{\circ}$ Division of Primary Care and Population Health, Department of Medicine, School of Medicine, Stanford University, Stanford, California; ' Division of Hospital Medicine, Department of Pediatrics, Children's National Medical Center, Washington, DC; ${ }^{8}$ Department of Medicine, School of Medicine, Stanford University, Stanford, California; ${ }^{9}$ Division of Hospital Medicine, Department of Medicine, School of Medicine, Stanford University, Stanford, California; ${ }^{10}$ Medicine Residency Program, Department of Medicine, Stanford School of Medicine; ${ }^{11}$ Division of General Internal Medicine, Department of Medicine, University of California, San Francisco, San Francisco, California.

BACKGROUND: Shared decision-making (SDM) improves patient engagement and may improve outpatient health outcomes. Little is known about inpatient SDM.

OBJECTIVE: To assess overall quality, provider behaviors, and contextual predictors of SDM during inpatient rounds on medicine and pediatrics hospitalist services.

DESIGN: A 12-week, cross-sectional, single-blinded observational study of team SDM behaviors during rounds, followed by semistructured patient interviews.

SETTING: Two large quaternary care academic medical centers.

PARTICIPANTS: Thirty-five inpatient teams (18 medicine, 17 pediatrics) and 254 unique patient encounters (117 medicine, 137 pediatrics).

INTERVENTION: Observational study.

MEASUREMENTS: We used a 9-item Rochester Participatory Decision-Making Scale (RPAD) measured team-level SDM behaviors. Same-day interviews using a modified RPAD assessed patient perceptions of SDM.
RESULTS: Characteristics associated with increased SDM in the multivariate analysis included the following: service, patient gender, timing of rounds during patient's hospital stay, and amount of time rounding per patient $(P<.05)$. The most frequently observed behaviors across all services included explaining the clinical issue and matching medical language to the patient's level of understanding. The least frequently observed behaviors included checking understanding of the patient's point of view, examining barriers to follow-through, and asking if the patient has any questions. Patients and guardians had substantially higher ratings for SDM quality compared to peer observers (7.2 vs 4.4 out of 9).

CONCLUSIONS: Important opportunities exist to improve inpatient SDM. Team size, number of learners, patient census, and type of decision being made did not affect SDM, suggesting that even large, busy services can perform SDM if properly trained. Journal of Hospital Medicine 2018;13:453-461. Published online first February 5, 2018. (C) 2018 Society of Hospital Medicine

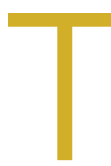

he ethos of medicine has shifted from paternalistic, physician-driven care to patient autonomy and engagement, in which the physician shares information and advises. ${ }^{1-3}$ Although there are ethical, legal, and practical reasons to respect patient preferences, ${ }^{1-4}$ patient engagement also fosters

\footnotetext{
*Address for correspondence: Rebecca Blankenburg, MD, MPH, Department of Pediatrics, School of Medicine, Stanford University, 725 Welch Road, MC 5906, Palo Alto, CA 94304; Telephone: 650-497-8979; Fax: 650-497-8228; E-mail: rblanke@stanford.edu

Additional Supporting Information may be found in the online version of this article.
}

Received: April 5, 2017; Revised: October 10, 2017; Accepted: October 19, 2017 () 2018 Society of Hospital Medicine DOI 10.12788/jhm.2909 quality and safety ${ }^{5}$ and may improve clinical outcomes. ${ }^{5-8}$ Patients whose preferences are respected are more likely to trust their doctor, feel empowered, and adhere to treatments. ${ }^{9}$

Providers may partner with patients through shared decision-making (SDM). ${ }^{10,11}$ Several SDM models describe the process of providers and patients balancing evidence, preferences and context to arrive at a clinical decision. ${ }^{12-15}$ The National Academy of Medicine and the American Academy of Pediatrics has called for more SDM, ${ }^{16,17}$ including when clinical evidence is limited, ${ }^{2}$ equally beneficial options exist, ${ }^{18}$ clinical stakes are high, ${ }^{19}$ and even with deferential patients. ${ }^{20}$ Despite its value, SDM does not reliably occur ${ }^{21,22}$ and SDM training is often unavailable. ${ }^{4}$ Clinical decision tools, patient education aids, and various training interventions have shown promising, although inconsistent results. ${ }^{23,24}$ 
Little is known about SDM in inpatient settings where unique patient, clinician, and environmental factors may influence SDM. This study describes the quality and possible predictors of inpatient SDM during attending rounds in 4 academic training settings. Although SDM may occur anytime during a hospitalization, attending rounds present a valuable opportunity for SDM observation given their centrality to inpatient care and teaching. ${ }^{25,26}$ Because attending physicians bear ultimate responsibility for patient management, we examined whether SDM performance varies among attendings within each service. In addition, we tested the hypothesis that service-level, team-level, and patient-level features explain variation in SDM quality more than individual attending physicians. Finally, we compared peer-observer perspectives of SDM behaviors with patient and/or guardian perspectives.

\section{METHODS}

\section{Study Design and Setting}

This cross-sectional, observational study examined the diversity of SDM practice within and between 4 inpatient services during attending rounds, including the internal medicine and pediatrics services at Stanford University and the University of California, San Francisco (UCSF). Both institutions provide quaternary care to diverse patient populations with approximately half enrolled in Medicare and/or Medicaid.

One institution had 42 internal medicine (Med-1) and 15 pediatric hospitalists (Peds-1) compared to 8 internal medicine (Med-2) and 12 pediatric hospitalists (Peds-2) at the second location. Both pediatric services used family-centered rounds that included discussions between the patients' families and the whole team. One medicine service used a similar rounding model that did not necessarily involve the patients' families. In contrast, the smaller medicine service typically began rounds by discussing all patients in a conference room and then visiting select patients afterwards.

From August 2014 to November 2014, peer observers gathered data on team SDM behaviors during attending rounds. After the rounding team departed, nonphysician interviewers surveyed consenting patients' (or guardians') views of the SDM experience, yielding paired evaluations for a subset of SDM encounters. Institutional review board approval was obtained from Stanford University and UCSF.

\section{Participants and Inclusion Criteria}

Attending physicians were hospitalists who supervised rounds at least 1 month per year, and did not include those conducting the study. All provided verbal assent to be observed on 3 days within a 7-day period. While team composition varied as needed (eg, to include the nurse, pharmacist, interpreter, etc), we restricted study observations to those teams with an attending and at least one learner (eg, resident, intern, medical student) to capture the influence of attending physicians in their training role. Because services vary in number of attendings on staff, rounds assigned per attending, and patients per round, it was not possible to enroll equal sample sizes per service in the study.

Nonintensive care unit patients who were deemed medically stable by the team were eligible for peer observation and participation in a subsequent patient interview once during the study period. Pediatric patients were invited for an interview if they were between 13 and 21 years old and had the option of having a parent or guardian present; if the pediatric patients were less than 13 years old or they were not interested in being interviewed, then their parents or guardians were invited to be interviewed. Interpreters were on rounds, and thus, non-English participants were able to participate in the peer observations, but could not participate in patient interviews because interpreters were not available during afternoons for study purposes. Consent was obtained from all participating patients and/or guardians.

\section{Data Collection \\ Round and Patient Characteristics}

Peer observers recorded rounding, team, and patient characteristics using a standardized form. Rounding data included date, attending name, duration of rounds, and patient census. Patient level data included the decision(s) discussed, the seniority of the clinician leading the discussion, team composition, minutes spent discussing the patient (both with the patient and/or guardian and total time), hospitalization week, and patient's primary language. Additional patient data obtained from electronic health records included age, gender, race, ethnicity, date of admission, and admitting diagnosis.

\section{SDM Measures}

Peer-observed SDM behaviors were quantified per patient encounter using the 9-item Rochester Participatory Decision-Making Scale (RPAD), with credit given for SDM behaviors exhibited by anyone on the rounding team (team-level metric). ${ }^{27}$ Each item was scored on a 3 -point scale $(0=$ absent, $0.5=$ partial, and 1 = present) for a maximum of 9 points, with higher scores indicating higher-quality SDM (Peer-RPAD Score). We created semistructured patient interview guides by adapting each RPAD item into layperson language (Patient-RPAD Score) and adding open-ended questions to assess the patient experience.

\section{Peer-Observer Training}

Eight peer-observers ( 7 hospitalists and 1 palliative care physician) were trained to perform RPAD ratings using videos of patient encounters. Initially, raters viewed videos together and discussed ratings for each RPAD item. The observers incorporated behavioral anchors and clinical examples into the development of an RPAD rating guide, which they subsequently used to independently score 4 videos from an online medical communication library. ${ }^{28}$ These scores were discussed to resolve any differences before 4 additional videos were independently viewed, scored, and compared. Interrater reliability was achieved when the standard deviation of summed SDM scores across raters was less than 1 for all 4 videos.

\section{Patient Interviewers}

Interviewers were English-speaking volunteers without formal medical training. They were educated in hospital etiquette by a physician and in administering patient interviews through 

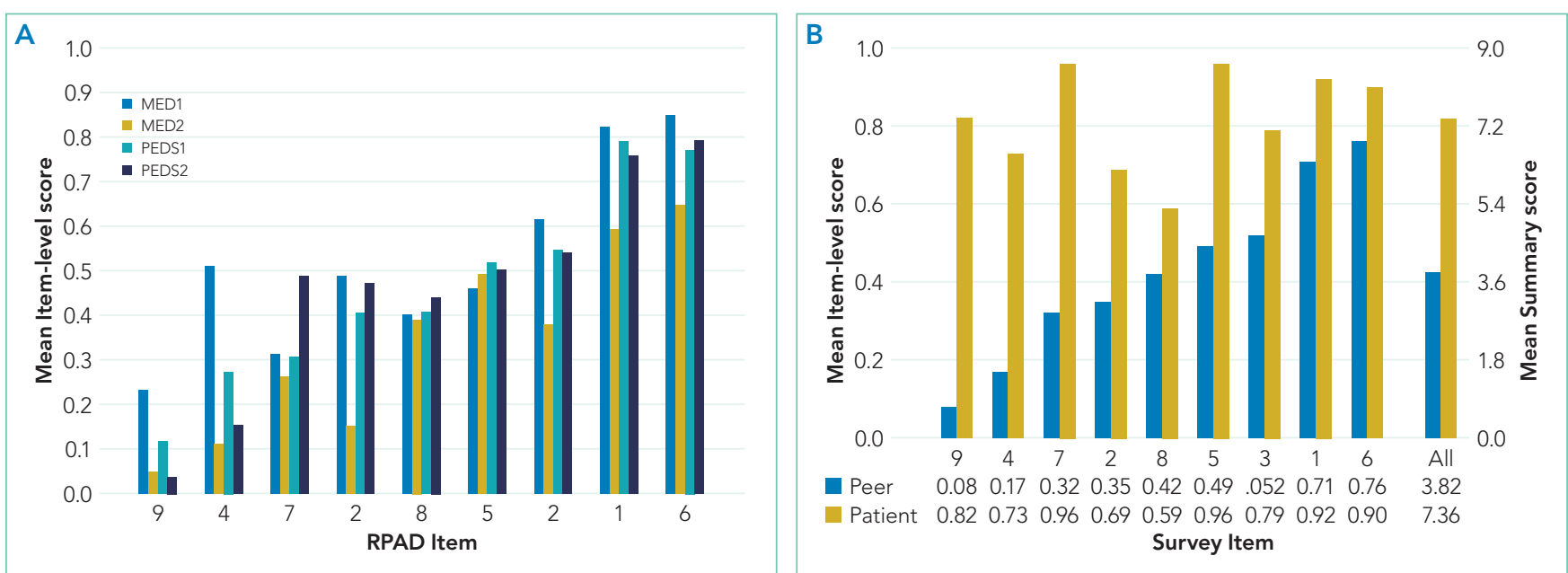

FIG. (A) Item-level Peer Ratings of Shared Decision Making by Service, among 254 SDM encounters, ordered by overall Peer-RPAD Scores. (B) Item-level Peer vs. Patient Ratings of Shared Decision Making, among 149 patient/guardian respondents to patient interviews, ordered by overall Peer-RPAD Scores.

NOTE: RPAD Items: 1=Team clearly explained medical issue or decision to be made; $2=$ Team discussed alternatives or uncertainties; $3=$ Team checked for patient agreement with plan; $4=$ Team examined barriers to follow through with treatment plan; $5=$ Team provided opportunity for patient to ask questions to ensure understanding; $6=$ Patient understood what Team was saying; $7=$ Team asked if patient had any questions; $8=$ Team asked open-ended questions; $9=$ Team checked own understanding of patient's point of view.

peer-to-peer role playing and an observation and feedback interview with at least 1 patient.

\section{Data Analysis}

The analysis set included every unique patient with whom a medical decision was made by an eligible clinical team. To account for the nested study design (patient-level scores within rounds, rounds within attending, and attendings within service), we used mixed-effects models to estimate mean (summary or item) RPAD score by levels of fixed covariate(s). The models included random effects accounting for attending-level and round-level correlations among scores via variance components, and allowing the attending-level random effect to differ by service. Analyses were performed using SAS version 9.4 (SAS Institute Inc, Cary, NC). We used descriptive statistics to summarize round- and patient-level characteristics.

\section{SDM Variation by Attending and Service}

Box plots were used to summarize raw patient-level, PeerRPAD scores by service and attending. By using the methods described above, we estimated the mean score overall and by service. In both models, we examined the statistical significance of service-specific variation in attending-level random effects by using likelihood-ratio test (LRT) to compare models.

\section{SDM Variation by Round and Patient Characteristics}

We used the models described above to identify covariates associated with Peer-RPAD scores. We fit univariate models separately for each covariate, then fit 2 multivariable models, including (1) all covariates and (2) all effects significant in either model at $P \leq .20$ according to $F$ tests. For uniformity of presentation, we express continuous covariates categorically; however, we report $P$ values based on continuous versions. Means generated by the multivariable models were calculated at the mean values of all other covariates in model.

\section{Patient-Level RPAD Data}

A subsample of patients completed semistructured interviews with analogous RPAD questions. To identify possible selection bias in the full sample, we summarized response rates by service and patient language and modeled Peer-RPAD scores by interview response status. Among responders, we estimated the mean Peer-RPAD and Patient-RPAD scores and their paired differences and correlations, testing for non-zero correlations via the Spearman rank test.

\section{RESULTS}

\section{All Patient Encounters}

A total of 35 attendings (18 medicine, 17 pediatrics) were observed, representing $51 \%$ of 69 eligible attendings. By design, study observations included a median of 3 rounds per attending (range 1-5), summing to 88 total rounds (46 medicine, 42 pediatrics) and 783 patient encounters (388 medicine, 395 pediatrics; Table 1).

The median duration of rounding sessions was 1.8 hours, median patient census was 9 , and median patient encounter was 13 minutes. The duration of rounds and minutes per patient were longest at Med-2 and shortest at Peds-1. See Table 1 for other team characteristics.

\section{Peer Evaluations of SDM Encounters Characteristics of Patients}

We observed SDM encounters in 254 unique patients $(117$ medicine, 137 pediatrics), representing $32 \%$ of all observed encounters. Patient mean age was 56 years for medicine and 7.4 years for pediatrics. Overall, $54 \%$ of patients were white, $11 \%$ were Asian, and $10 \%$ were African American; race was not reported for $21 \%$ of patients. Pediatrics services had more SDM encounters with Hispanic patients (31\% vs. 9\%) and Spanish-speaking patients (14\% vs < 2\%; Table 2). Patient complexity ranged from case mix index (CMI) 1.17 (Med-1) to 2. 11 (Peds-1). 
TABLE 1. Characteristics of Rounding Sessions Observed During the Study

\begin{tabular}{|c|c|c|c|c|c|}
\hline Characteristics & Total & Med-1 & Med-2 & Peds-1 & Peds-2 \\
\hline Attending hospitalists, $\mathrm{n}$ & 35 & 6 & 12 & 9 & 8 \\
\hline Rounding sessions, n & 88 & 13 & 33 & 24 & 18 \\
\hline Rounding sessions per attending, median (min-max) & $3(1-5)$ & $2.5(1-3)$ & $3(2-3)$ & $3(1-4)$ & $2(1-5)$ \\
\hline Patients encounters per round, $\mathrm{n}$, median, (min-max) & $7969(3-14)$ & $1069(3-14)$ & $2828(4-11)$ & $25011(5-14)$ & $1589(4-13)$ \\
\hline Duration of round (hours), median (min-max) & $1.8(0.4-4.5)$ & $1.7(0.8-3.7)$ & $2.5(1.4-4.5)$ & $1.4(0.4-2.5)$ & $1.8(1.0-2.4)$ \\
\hline Minutes per patient encounter, ${ }^{a}$ median (Q1, Q3) & $13(10-18)$ & $15(10-18)$ & $18(15-20)$ & $8(7-11)$ & $13(11-14)$ \\
\hline Team size, ${ }^{b}$ median (min-max) & $8.4(3-17)$ & $6.4(3-9)$ & $6.8(3-11)$ & $10.2(4-14)$ & $10.3(4-17)$ \\
\hline \multicolumn{6}{|l|}{ Team members, ${ }^{b}$ ( $\%$ of team size) } \\
\hline Attending physicians/fellows & $1.3(15 \%)$ & $1.1(18 \%)$ & $1.1(19 \%)$ & $1.3(14 \%)$ & $1.1(11 \%)$ \\
\hline Trainees ${ }^{c}$ & $4.0(49 \%)$ & $2.7(45 \%)$ & $3.2(54 \%)$ & $4.5(47 \%)$ & $4.7(45 \%)$ \\
\hline Nurses & $0.5(6 \%)$ & $0(0 \%)$ & $0.2(3 \%)$ & $0.9(9 \%)$ & $0.8(8 \%)$ \\
\hline \multirow{2}{*}{$\begin{array}{l}\text { Respiratory therapists, pharmacists, case managers, social } \\
\text { workers, interpreters }\end{array}$} & $1.1(14 \%)$ & $0.6(8 \%)$ & $0.3(6 \%)$ & $1.3(13 \%)$ & $2.6(25 \%)$ \\
\hline & $1.4(17 \%)$ & $1.7(28 \%)$ & $1.1(18 \%)$ & $1.4(15 \%)$ & $1.2(11 \%)$ \\
\hline \multicolumn{6}{|l|}{ Individual presenting the patient, ${ }^{b} \%$ of unique patients } \\
\hline Medical student & $35 \%$ & $26 \%$ & $30 \%$ & $52 \%$ & $29 \%$ \\
\hline Intern & $52 \%$ & $50 \%$ & $39 \%$ & $48 \%$ & $71 \%$ \\
\hline Resident & $12 \%$ & $24 \%$ & $27 \%$ & $0 \%$ & $0 \%$ \\
\hline Attending & $1.6 \%$ & $0 \%$ & $4.8 \%$ & $0 \%$ & $0 \%$ \\
\hline
\end{tabular}

aRound-level average minutes per patient was calculated as the round duration divided by the patient census.

${ }^{\mathrm{b}}$ Team size and composition and presenting physician could vary among patients within a round.

cResident/intern/medical student.

Includes the peer observer.

NOTE: Abbreviations: min, minimum of the distribution of the characteristic; max, maximum of the distribution of the characteristic; Q1, first quartile; Q3, third quartile.

Teams spent a median of 13 minutes per SDM encounter, which was not higher than the round median. SDM topics discussed included $47 \%$ treatment, $15 \%$ diagnostic, $30 \%$ both treatment and diagnostic, and $7 \%$ other.

\section{Variation in SDM Quality Among Attending Physicians}

Overall Peer-RPAD Scores were normally distributed. After adjusting for the nested study design, the overall mean (standard error) score was 4.16 (0.11). Score variability among attendings differed significantly by service (LRT $P=.0067)$. For example, raw scores were lower and more variable among attending physicians at Med-2 than other among attendings in other services (see Appendix Figure in Supporting Information). However, when service was included in the model as a fixed effect, mean scores varied significantly, from 3.0 at Med-2 to 4.7 at Med-1 $(P<.0001)$, but the random variation among attendings no longer differed significantly by service $(P=.13)$. This finding supports the hypothesis that service-level influences are stronger than influences of individual attending physicians, that is, that variation between services exceeded variation among attendings within service.
Aspects of SDM That Are More Prevalent on Rounds Based on Peer-RPAD item scores, the most frequently observed behaviors across all services included "Matched medical language to the patient's level of understanding" (Item 6, $0.75)$ and "Explained the clinical issue or nature of the decision" (Item 1, 0.74; panel A of Figure). The least frequently observed behaviors included "Asked if patient had any questions" (Item 7, 0.34), "Examined barriers to follow-through with the treatment plan" (Item 4, 0.15), and "Checked understanding of the patient's point of view" (Item 9, 0.06).

\section{Rounds and Patient Characteristics Associated With Peer-RPAD Scores}

In univariate models, Peer-RPAD scores decreased significantly with round-level average minutes per patient and were elevated during a patient's second week of hospitalization. In the multivariable model including all covariates in Table 3, mean Peer-RPAD scores varied by service (lower at Med-2 than elsewhere), patient gender (slightly higher among women and girls), week of hospitalization (highest during the second week), and time spent with the patient and/or guardian (more 
TABLE 2. Rounding Characteristics of Unique Patient Encounters Involving SDM

\begin{tabular}{|c|c|c|c|c|c|}
\hline Characteristics & Total & Med-1 & Med-2 & Peds-1 & Peds-2 \\
\hline Unique patients, $\mathrm{n}$ ( $\%$ of patient encounters); & $254(32 \%)$ & $34(32 \%)$ & $83(29 \%)$ & $62(25 \%)$ & $75(47 \%)$ \\
\hline median (min-max) per round & $3(1-8)$ & $3(1-5)$ & $2(1-6)$ & $2(1-6)$ & $4(2-8)$ \\
\hline Patient and/or guardian survey, $\mathrm{n}(\%)$ & $149(59 \%)$ & $9(26 \%)$ & $57(69 \%)$ & $29(47 \%)$ & $54(72 \%)$ \\
\hline Age of patient, a median (Q1-Q3) & $17(5.0-56)$ & $54(43-67)$ & $60(41-71)$ & $4(1.3-9.0)$ & $7(5.0-15)$ \\
\hline Male patient, n (\%) & $128(51 \%)$ & $18(55 \%)$ & $27(33 \%)$ & $48(77 \%)$ & $35(47 \%)$ \\
\hline \multicolumn{6}{|l|}{ Race, n (\%) } \\
\hline White, $n(\%)$ & $136(54 \%)$ & $18(53 \%)$ & $45(54 \%)$ & $35(56 \%)$ & $38(51 \%)$ \\
\hline Asian & $28(11 \%)$ & $2(5.9 \%)$ & $12(14 \%)$ & $9(15 \%)$ & $5(6.7 \%)$ \\
\hline African American & $26(10 \%)$ & $7(21 \%)$ & $15(18 \%)$ & $1(1.6 \%)$ & $3(4.0 \%)$ \\
\hline Pacific Islander/Native American & $10(3.9 \%)$ & $1(2.9 \%)$ & $3(3.6 \%)$ & $4(6.4 \%)$ & $2(2.7 \%)$ \\
\hline Hispanic, n (\%) & $52(20 \%)$ & $5(15 \%)$ & $5(6.0 \%)$ & $35(56 \%)$ & $22(29 \%)$ \\
\hline \multicolumn{6}{|l|}{ Language } \\
\hline English & $220(87 \%)$ & $31(91 \%)$ & $73(88 \%)$ & $51(82 \%)$ & $65(87 \%)$ \\
\hline Spanish & $21(8.3 \%)$ & $1(2.9 \%)$ & $1(1.2 \%)$ & $10(16 \%)$ & $9(12 \%)$ \\
\hline Other & $13(5.1 \%)$ & $2(5.9 \%)$ & $9(11 \%)$ & $1(1.6 \%)$ & $1(1.3 \%)$ \\
\hline CMI, mean & & 1.17 & 1.49 & 2.11 & 1.31 \\
\hline Hospitalization day, median (Q1-Q3) & $2(1-4)$ & $2(1-8)$ & $2(1-6)$ & $1(1-3)$ & $3(1-4)$ \\
\hline Total minutes rounding per patient, median (Q1-Q3) & $13(9-18)$ & $12(7-18)$ & $15(12-25)$ & $14(12-18)$ & $10(6-13)$ \\
\hline $\begin{array}{l}\text { Minutes with patient and/or guardian present, per } \\
\text { patient, median (Q1-Q3) }\end{array}$ & $12(8-17)$ & $9(6-17)$ & $13(9-21)$ & $14(12-18)$ & $10(6-13)$ \\
\hline \multicolumn{6}{|l|}{ Types of decisions discussed } \\
\hline Treatment $^{b}$ & $120(47 \%)$ & $11(32 \%)$ & 49 (59\%) & $34(55 \%)$ & $26(35 \%)$ \\
\hline Diagnosis $^{b}$ & $39(15 \%)$ & $10(29 \%)$ & $10(12 \%)$ & $10(16 \%)$ & $9(12 \%)$ \\
\hline Diagnosis and treatment ${ }^{b}$ & $77(30 \%)$ & $9(26 \%)$ & $19(23 \%)$ & $16(26 \%)$ & $33(44 \%)$ \\
\hline Other ${ }^{b}$ & $18(7.1 \%)$ & $4(12 \%)$ & $5(6.0 \%)$ & $2(3.2 \%)$ & $7(9.3 \%)$ \\
\hline
\end{tabular}

${ }^{a}$ Missing for one patient.

${ }^{\mathrm{b}} \mathrm{Can}$ include discussion of other decisions, such as discharge.

NOTE: Abbreviations: CMI, case mix index; Q1, first quartile; Q3, third quartile.

time correlated with higher scores). In a reduced multivariable model restricted to the covariates that were statistically significant in either model $(P \leq .20)$, all 5 associations remained significant $P \leq .05$. However, the difference in means by gender was only 0.3 , and only $18 \%$ of patients were hospitalized for more than 1 week.

Patient-RPAD Results: Dissimilar Perspectives of Patients and/or Guardians and Physician Observers Of 254 peer-evaluated SDM encounters, 149 (59\%) patients and/or guardians were available and consented to same-day interviews, allowing comparison of paired peer and patient evaluations of SDM in this subset. The response rate was $66 \%$ among patients whose primary language was English versus $15 \%$ among others. Peer-RPAD scores by interview response status were similar overall (responders, 4.17; nonresponders,
4.13; $P=.83$ ) and by service (interaction $P=.30$ ).

Among responders, mean Patient-RPAD scores were 6.8 to 7.1 for medicine services and 7.6 to 7.8 for pediatric services $(P=.01)$. The overall mean Patient-RPAD score, 7.46 , was significantly greater than the paired Peer-RPAD score by 3.5 ( $P=$ .011); however, correlations were not statistically significantly different from 0 (by service, each $P>$.12).

To understand drivers of the differences between Peer-RPAD and Patient-RPAD scores, we analyzed findings by item. Each mean patient-item score exceeded its peer counterpart $(P \leq .01$; panel B of Figure). Peer-item scores fell below 33\% on 2 items (Items 9 and 4) and only exceeded 67\% on 2 items (Items 1 and 6), whereas patient-item scores ranged from $60 \%$ (Item 8) to $97 \%$ (Item 7). Three paired differences exceeded 50\% (Items 9, 4, and 7) and 3 were below $20 \%$ (Items 6, 8 and 1), underlying the lack of correlation between peer and patient scores. 
TABLE 3. Associations of Peer-RPAD Scores with Levels of Rounding and Team Characteristics

\begin{tabular}{|c|c|c|c|c|c|c|c|}
\hline \multirow[b]{2}{*}{ Characteristics } & \multirow[b]{2}{*}{$\begin{array}{l}\text { Patients (\% of SDM } \\
\text { encounters) }\end{array}$} & \multicolumn{2}{|c|}{ Univariate Models } & \multicolumn{2}{|c|}{ Full Multivariable Model } & \multicolumn{2}{|c|}{ Reduced Multivariable Model } \\
\hline & & RPAD Score, mean & $\begin{array}{c}\mathrm{F} \text { test } \\
P \text { value (nDF) }\end{array}$ & RPAD Score, mean & $\begin{array}{c}\mathrm{F} \text { test } \\
P \text { value (nDF) }\end{array}$ & RPAD Score, mean & $\begin{array}{c}\mathrm{F} \text { test } \\
P \text { value (nDF) }\end{array}$ \\
\hline Overall & $254(100 \%)$ & 4.16 & & 4.32 & & 4.35 & \\
\hline \multicolumn{8}{|l|}{ Round Characteristics } \\
\hline Service & & & $<.001(3)$ & & $.0003(3)$ & & $<.0001(3)$ \\
\hline Med-1 & $34(13 \%)$ & 4.72 & & 4.74 & & 5.03 & \\
\hline Med-2 & $83(33 \%)$ & 3.04 & & 3.27 & & 3.42 & \\
\hline Peds-1 & $62(24 \%)$ & 4.26 & & 4.64 & & 4.44 & \\
\hline Peds-2 & $75(30 \%)$ & 4.14 & & 4.64 & & 4.53 & \\
\hline Round census $^{\mathrm{a}}$ & & & $.48(1)^{b}$ & & $.87(1)^{b}$ & & \\
\hline 3-7 & $51(20 \%)$ & 4.12 & & 4.10 & & & \\
\hline 8-9 & $95(37 \%)$ & 4.16 & & 4.20 & & & \\
\hline $10-11$ & $53(21 \%)$ & 4.26 & & 4.62 & & & \\
\hline $12-14$ & $55(22 \%)$ & 4.13 & & 4.37 & & & \\
\hline Round duration ${ }^{\mathrm{a}}$ & & & $.25(1)^{b}$ & & $.38(1)^{\mathrm{b}}$ & & \\
\hline$<1.5$ hours & $54(21 \%)$ & 4.32 & & 4.71 & & & \\
\hline 1.5-1.99 hours & $80(32 \%)$ & 4.27 & & 4.52 & & & \\
\hline 2.0-2.49 hours & $63(25 \%)$ & 3.83 & & 3.98 & & & \\
\hline$\geq 2.5$ hours & $57(22 \%)$ & 3.85 & & 4.07 & & & \\
\hline Average minutes per patient ${ }^{\mathrm{a}}$ & & & $.038(1)^{\mathrm{b}}$ & & $0.24(1)^{b}$ & & $.033(1)^{b}$ \\
\hline$<10$ minutes & $56(22 \%)$ & 4.20 & & 4.23 & & 4.49 & \\
\hline $10.0-14.9$ & $107(42 \%)$ & 4.17 & & 4.80 & & 4.74 & \\
\hline $15.0-19.9$ & $53(21 \%)$ & 3.70 & & 4.29 & & 4.24 & \\
\hline$\geq 20.0$ & $38(15 \%)$ & 3.51 & & 3.97 & & 3.94 & \\
\hline \multicolumn{8}{|l|}{ Team characteristics } \\
\hline Team size & & & $.77(1)^{b}$ & & $.25(1)^{b}$ & & \\
\hline 3-6 members & $87(34 \%)$ & 4.20 & & 4.52 & & & \\
\hline 7-8 members & $62(24 \%)$ & 4.23 & & 4.61 & & & \\
\hline 9-10 members & $53(21 \%)$ & 4.06 & & 4.10 & & & \\
\hline 11-17 members & $52(20 \%)$ & 4.18 & & 4.05 & & & \\
\hline Trainee percentage on team & & & $.27(1)^{b}$ & & $.57(1)^{b}$ & & \\
\hline$<40 \%$ & $52(20 \%)$ & 4.29 & & 4.50 & & & \\
\hline $40.0 \%$ to $49.9 \%$ & $55(22 \%)$ & 4.27 & & 4.34 & & & \\
\hline $50.0 \%$ to $59.9 \%$ & $91(36 \%)$ & 4.01 & & 4.28 & & & \\
\hline$\geq 60 \%$ & $56(22 \%)$ & 3.92 & & 4.17 & & & \\
\hline Presenting MD & & & $.95(3)$ & & $.86(3)$ & & \\
\hline Medical student & $88(35 \%)$ & 4.11 & & 4.18 & & & \\
\hline Intern & $132(52 \%)$ & 4.19 & & 4.22 & & & \\
\hline Resident & $30(12 \%)$ & 4.24 & & 4.25 & & & \\
\hline Attending & $4(2 \%)$ & 4.24 & & 4.63 & & & \\
\hline
\end{tabular}

aBecause the outcome is patient-level, patient-level distributions are tabled for round-level covariates.

${ }^{b}$ Test for linear association uses continuous version of covariate, thus nDF of F test has $1 \mathrm{DF}$.

NOTE: According to univariate models (include 1 covariate) and 2 multivariable models, these characteristics are illustrated via mean Peer-RPAD scores and $P$ values from $F$ tests. The full multivariable model includes all covariates tabulated, and the reduced multivariable model includes covariates that were statistically significant at $P \leq .20$ in either univariate or the full multivariable model according to F tests. Abbreviations: DF, degrees of freedom; MD, medical doctor; $n D F$, numerator degrees of freedom; RPAD, Rochester Participatory Decision-Making Scale; SDM, shared decision making. 
TABLE 4. Associations of Peer-RPAD Scores with Levels of Patient Characteristics

\begin{tabular}{|c|c|c|c|c|c|c|c|}
\hline Patient Characteristics & $\mathrm{N}$ & $\begin{array}{l}\text { Peer-RPAD Score, } \\
\text { mean }\end{array}$ & $\begin{array}{c}F \text { test } \\
P \text { value (nDF) }\end{array}$ & $\begin{array}{l}\text { Peer-RPAD Score, } \\
\text { mean }\end{array}$ & $\begin{array}{c}F \text { test } \\
P \text { value (nDF) }\end{array}$ & $\begin{array}{l}\text { Peer-RPAD Score, } \\
\text { mean }\end{array}$ & $\begin{array}{c}\mathrm{F} \text { test } \\
P \text { value (nDF) }\end{array}$ \\
\hline Age & & & $.92(1)$ & & $.67(1)$ & & \\
\hline Pediatric & $137(54 \%)$ & 4.17 & & & & & \\
\hline Adult & $72(28 \%)$ & 3.21 & & & & & \\
\hline Geriatric & $45(18 \%)$ & 3.33 & & & & & \\
\hline Gender $^{\mathrm{a}}$ & & & $.19(1)$ & & $.052(1)$ & & $.028(1)$ \\
\hline Female & $122(49 \%)$ & 4.27 & & 4.49 & & 4.52 & \\
\hline Male & $128(51 \%)$ & 4.06 & & 4.15 & & 4.19 & \\
\hline Race & & & $.81(4)$ & & $.68(4)$ & & \\
\hline White & $136(54 \%)$ & 4.24 & & 4.45 & & & \\
\hline Asian & $28(11 \%)$ & 4.18 & & 4.19 & & & \\
\hline African American & $26(10 \%)$ & 4.19 & & 4.50 & & & \\
\hline Pacific Islander/Native American & $10(3.9 \%)$ & 3.85 & & 4.20 & & & \\
\hline Other & $54(21 \%)$ & 4.05 & & 4.26 & & & \\
\hline Week of rounding encounter & & & $.090(2)$ & & $.023(2)$ & & $.024(2)$ \\
\hline $0-6$ days & $209(82 \%)$ & 4.10 & & 4.00 & & 4.02 & \\
\hline $7-13$ days & $28(11 \%)$ & 4.60 & & 4.67 & & 4.59 & \\
\hline 14-161 days & $17(7 \%)$ & 4.38 & & 4.29 & & 4.46 & \\
\hline Decision type & & & $.33(3)$ & & $.31(3)$ & & \\
\hline Treatment and Diagnosis & $77(30 \%)$ & 4.29 & & 4.55 & & & \\
\hline Treatment & $120(47 \%)$ & 4.05 & & 4.30 & & & \\
\hline Diagnosis & $39(15 \%)$ & 3.92 & & 3.97 & & & \\
\hline Other & $18(7 \%)$ & 4.31 & & 4.47 & & & \\
\hline \multirow{2}{*}{$\begin{array}{l}\text { Duration of patient encounter, includ- } \\
\text { ing time on SDM }\end{array}$} & & & & & $.0096(1)^{\mathrm{b}}$ & & \\
\hline & $76(30 \%)$ & 4.04 & $.30(1)$ & 3.90 & & 3.96 & $.024(1)^{b}$ \\
\hline$<10$ minutes & $69(27 \%)$ & 4.20 & & 4.19 & & 4.25 & \\
\hline 10.0-14.9 minutes & $53(21 \%)$ & 4.47 & & 4.51 & & 4.54 & \\
\hline 15.0-19.9 minutes & $21(8.3 \%)$ & 3.88 & & 3.80 & & 3.97 & \\
\hline 20.0-24.9 minutes & $21(4.7 \%)$ & 4.39 & & 4.86 & & 4.74 & \\
\hline 25.0-29.9 minutes & $23(9.1 \%)$ & 4.26 & & 4.66 & & 4.66 & \\
\hline$\geq 30$ minutes & & & & & & & \\
\hline
\end{tabular}

anspecified: age for 1 patient at Med-1.

'Test for linear association uses continuous version of covariate, thus $\mathrm{nDF}$ of $\mathrm{F}$ test has $1 \mathrm{DF}$.

NOTE: According to univariate models (include 1 covariate) and 2 multivariable models, these characteristics are illustrated via mean Peer-RPAD scores and $P$ values from $F$ tests. The full multivariable model includes all covariates tabulated, and the reduced multivariable model includes covariates that were statistically significant at $P \leq .20$ in either univariate or the full multivariable model according to F tests. Abbreviations: DF, degrees of freedom; nDF, numerator degrees of freedom; RPAD, Rochester Participatory Decision-Making Scale; SDM, shared decision making.

\section{DISCUSSION}

In this multisite study of SDM during inpatient attending rounds, SDM quality, specific SDM behaviors, and factors contributing to SDM were identified. Our study found an adjusted overall Peer-RPAD Score of 4.4 out of 9 , and found the following 3 SDM elements most needing improvement according to trained peer observers: (1) "Checking understanding of the patient's perspective", (2) "Examining barriers to follow-through with the treatment plan", and (3) "Asking if the patient has questions." Areas of strength included explaining the clinical issue or nature of the decision and matching medical language to the patient's level of understanding, with each rated highly by both peer-observers and patients. Broadly speaking, physicians were skillful in delivering information to patients but failed to solicit input from patients. Characteristics associated with increased SDM in the multivariate analysis included the following: service, patient gender, timing of rounds during patient's hospital stay, and amount of time rounding with each patient.

Patients similarly found that physicians could improve their abilities to elicit information from patients and families, noting the 3 lowest patient-rated SDM elements were as follows: (1) asking open-ended questions, (2) discussing alternatives or uncertainties, and (3) discussing barriers to treatment plan follow through. Overall, patients and guardians perceived the quantity and quality of SDM on rounds more favorably than peer observers, which is consistent with other studies of patient perceptions 
of communication. ${ }^{29-31}$ It is possible that patient ratings are more influenced by demand characteristics, fear of negatively impacting their patient-provider relationships, and conflation of overall satisfaction with quality of communication. ${ }^{32}$ This difference in patient perception of SDM is worthy of further study.

Prior work has revealed that SDM may occur infrequently during inpatient rounds. ${ }^{11}$ This study further elucidates specific SDM behaviors used along with univariate and multivariate modeling to explore possible contributing factors. The strengths and weaknesses found were similar at all 4 services and the influence of the service was more important than variability across attendings. This study's findings are similar to a study by Shields et al. ${ }^{33}$ in which the findings in a geographically different outpatient setting 10 years earlier suggesting global and enduring challenges to SDM. To our knowledge, this is the first published study to characterize inpatient SDM behaviors and may serve as the basis for future interventions.

Although the item-level components were ranked similarly across services, on average the summary Peer-RPAD score was lowest at Med-2, where we observed high variability within and between attendings, and was highest at Med-1, where variability was low. Med-2 carried the highest caseload and held the longest rounds, while Med-1 carried the lowest caseload, suggesting that modifiable burdens may hamper SDM performance. Prior studies suggest that patients are often selected based on teaching opportunities, immediate medical need and being newly admitted. ${ }^{34}$ The high scores at Med- 1 may reflect that service's prediscussion of patients during card-flipping rounds or their selection of which patients to round on as a team. Consistent with prior studies 29,35 of SDM and the family-centered rounding model, which includes the involvement of nurses, respiratory therapists, pharmacists, case managers, social workers, and interpreters on rounds, both pediatrics services showed higher SDM scores.

In contrast to prior studies, ${ }^{34,36}$ team size and number of learners did not affect SDM performance, nor did decision type. Despite teams having up to 17 members, 8 learners, and 14 complex patients, SDM scores did not vary significantly by team. Nonetheless, trends were in the directions expected: Scores tended to decrease as the team size or the percentage of trainees grew, and increased with the seniority of the presenting physician. Interestingly, SDM performance decreased with round-average minutes per patient, which may be measuring on-going intensity across cases that leads to exhaustion. Statistically significant patient factors for increased SDM included longer duration of patient encounters, second week of hospital stay, and female patient gender. Although we anticipated that the high number of decisions made early in hospitalization would facilitate higher SDM scores, continuity and stronger patient-provider relationships may enhance SDM. ${ }^{36}$ We report service-specific team and patient characteristics, in addition to SDM findings in anticipation that some readers will identify with 1 service more than others.

This study has several important limitations. First, our peer observers were not blinded and primarily observed encounters at their own site. To minimize bias, observers periodically rated videos to recalibrate RPAD scoring. Second, additional SDM conversations with a patient and/or guardian may have occurred outside of rounds and were not captured, and poor patient recall may have affected Patient-RPAD scores despite interviewer prompts and timeliness of interviews within 12 hours of rounds. Third, there might have been a selection bias for the one service who selected a smaller number of patients to see, compared with the three other services that performed bedside rounds on all patients. It is possible that attending physicians selected patients who were deemed most able to have SDM conversations, thus affecting RPAD scores on that service. Fourth, study services had fewer patients on average than other academic hospitals (median 9, range 3-14), which might limit its generalizability. Last, as in any observational study, there is always the possibility of the Hawthorne effect. However, neither teams nor patients knew the study objectives.

Nevertheless, important findings emerged through the use of RPAD Scores to evaluate inpatient SDM practices. In particular, we found that to increase SDM quality in inpatient settings, practitioners should (1) check their understanding of the patient's perspective, (2) examine barriers to follow-through with the treatment plan, and (3) ask if the patient has questions. Variation among services remained very influential after adjusting for team and patient characteristics, which suggests that "climate" or service culture should be targeted by an intervention, rather than individual attendings or subgroups defined by team or patient characteristics. Notably, team size, number of learners, patient census, and type of decision being made did not affect SDM performance, suggesting that even large, busy services can perform SDM if properly trained.

\section{Acknowledgments}

The authors thank the patients, families, pediatric and internal medicine residents, and hospitalists at Stanford School of Medicine and University of California, San Francisco School of Medicine for their participation in this study. We would also like to thank the student volunteers who collected patient perspectives on the encounters.

Disclosure: The author(s) declared no potential conflicts of interest with respect to the research, authorship, and/or publication of this article. The author(s) disclosed receipt of the following financial support for the research, authorship, and/or publication of this article: This study was supported by an $\mathrm{NIH} / \mathrm{NCCIH}$ grant R25 AT006573.

\section{References}

1. Braddock $\mathrm{CH}$. The emerging importance and relevance of shared decision making to clinical practice. Med Decis Mak. 2010;30(5 Suppl):5S-7S doi:10.1177/0272989X10381344.

2. Braddock $\mathrm{CH}$. Supporting shared decision making when clinical evidence is low. Med Care Res Rev MCRR. 2013;70(1 Suppl):129S-140S. doi:10.1177/1077558712460280.

3. Elwyn G, Tilburt J, Montori V. The ethical imperative for shared decision-making. Eur J Pers Centered Healthc. 2013;1(1):129-131. doi:10.5750/ ejpch.v1i1.645

4. Stiggelbout AM, Pieterse AH, De Haes JCJM. Shared decision making: Concepts, evidence, and practice. Patient Educ Couns. 2015;98(10):1172-1179. doi:10.1016/j.pec.2015.06.022.

5. Stacey D, Légaré $F$, Col NF, et al. Decision aids for people facing health treatment or screening decisions. Cochrane Database Syst Rev. 
2014;(10):CD001431. doi:10.1002/14651858.CD001431.pub4

6. Wilson SR, Strub P, Buist AS, et al. Shared treatment decision making improves adherence and outcomes in poorly controlled asthma. Am J Respir Crit Care Med. 2010;181(6):566-577. doi:10.1164/rccm.200906-0907OC.

7. Parchman ML, Zeber JE, Palmer RF. Participatory decision making, patient activation, medication adherence, and intermediate clinical outcomes in type 2 diabetes: a STARNet study. Ann Fam Med. 2010;8(5):410-417. doi:10.1370/ afm.1161

8. Weiner SJ, Schwartz A, Sharma G, et al. Patient-centered decision making and health care outcomes: an observational study. Ann Intern Med. 2013:158(8):573-579. doi:10.7326/0003-4819-158-8-201304160-00001.

9. Butterworth JE, Campbell JL. Older patients and their GPs: shared decision making in enhancing trust. Br J Gen Pract. 2014;64(628):e709-e718. doi:10.3399/bjgp14X682297.

10. Barry MJ, Edgman-Levitan S. Shared decision making--pinnacle of patient-centered care. N Engl J Med. 2012;366(9):780-781. doi:10.1056/NEJMp1109283.

11. Satterfield JM, Bereknyei S, Hilton JF, et al. The prevalence of social and behavioral topics and related educational opportunities during attending rounds. Acad Med J Assoc Am Med Coll. 2014;89(11):1548-1557. doi:10.1097/ ACM.0000000000000483

12. Charles C, Gafni A, Whelan T. Shared decision-making in the medical encounter: what does it mean? (or it takes at least two to tango). Soc Sci Med. 1997;44(5):681-692.

13. Elwyn G, Frosch D, Thomson R, et al. Shared decision making: a model for clinical practice. J Gen Intern Med. 2012;27(10):1361-1367. doi:10.1007/ s11606-012-2077-6.

14. Légaré F, St-Jacques S, Gagnon S, et al. Prenatal screening for Down syndrome: a survey of willingness in women and family physicians to engage in shared decision-making. Prenat Diagn. 2011;31(4):319-326. doi:10.1002/ pd.2624.

15. Satterfield JM, Spring B, Brownson RC, et al. Toward a Transdisciplinary Model of Evidence-Based Practice. Milbank O. 2009:87(2):368-390.

16. National Academy of Medicine. Crossing the quality chasm: a new health system for the 21st century. https://www.nationalacademies.org/ hmd/ /media/Files/Report\%20Files/2001/Crossing-the-Quality-Chasm/ Quality\%20Chasm\%202001\%20\%20report\%20brief.pdf. Accessed on November 30, 2016

17. Adams RC, Levy SE, Council on Children with Disabilities. Shared Decision-Making and Children with Disabilities: Pathways to Consensus. Pediatrics. 2017; 139(6):1-9.

18. Müller-Engelmann M, Keller H, Donner-Banzhoff N, Krones T. Shared decision making in medicine: The influence of situational treatment factors. Patient Educ Couns. 2011;82(2):240-246. doi:10.1016/j.pec.2010.04.028.

19. Whitney SN. A New Model of Medical Decisions: Exploring the Limits of Shared Decision Making. Med Decis Making. 2003;23(4):275-280. doi:10.1177/0272989X03256006.

20. Kehl KL, Landrum MB, Arora NK, et al. Association of Actual and Preferred Decision Roles With Patient-Reported Quality of Care: Shared Decision Making in Cancer Care. JAMA Oncol. 2015;1(1):50-58. doi:10.1001/jamaoncol.2014.112.
21. Couët N, Desroches $\mathrm{S}$, Robitaille $\mathrm{H}$, et al. Assessments of the extent to which health-care providers involve patients in decision making: a systematic review of studies using the OPTION instrument. Health Expect Int J Public Particip Health Care Health Policy. 2015;18(4):542-561. doi:10.1111/hex.12054.

22. Fowler FJ, Gerstein BS, Barry MJ. How patient centered are medical decisions?: Results of a national survey. JAMA Intern Med. 2013:173(13):12151221. doi:10.1001/jamainternmed.2013.6172.

23. Légaré F, Stacey D, Turcotte $S$, et al. Interventions for improving the adoption of shared decision making by healthcare professionals. Cochrane Database Syst Rev. 2014;(9):CD006732. doi:10.1002/14651858.CD006732.pub3.

24. Stacey D, Bennett CL, Barry MJ, et al. Decision aids for people facing health treatment or screening decisions. Cochrane Database Syst Rev. 2011;(10):CD001431. doi:10.1002/14651858.CD001431.pub3.

25. Di Francesco L, Pistoria MJ, Auerbach AD, Nardino RJ, Holmboe ES. Internal medicine training in the inpatient setting. A review of published educational interventions. J Gen Intern Med. 2005;20(12):1173-1180. doi:10.1111/j.15251497.2005.00250.x.

26. Janicik RW, Fletcher KE. Teaching at the bedside: a new model. Med Teach 2003;25(2):127-130.

27. Shields CG, Franks P, Fiscella K, Meldrum S, Epstein RM. Rochester Participatory Decision-Making Scale (RPAD): reliability and validity. Ann Fam Med. 2005:3(5):436-442. doi:10.1370/afm.305.

28. DocCom - enhancing competence in healthcare communication. https://webcampus.drexelmed.edu/doccom/user/. Accessed on November 30, 2016.

29. Bailey SM, Hendricks-Muñoz KD, Mally P. Parental influence on clinical management during neonatal intensive care: a survey of US neonatologists J Matern Fetal Neonatal Med. 2013;26(12):1239-1244. doi:10.3109/1476705 8.2013.776531

30. Janz NK, Wren PA, Copeland LA, Lowery JC, Goldfarb SL, Wilkins EG. Patient-physician concordance: preferences, perceptions, and factors influencing the breast cancer surgical decision. J Clin Oncol. 2004;22(15):3091-3098. doi:10.1200/JCO.2004.09.069

31. Schoenborn NL, Cayea D, McNabney M, Ray A, Boyd C. Prognosis communication with older patients with multimorbidity: Assessment after an educational intervention. Gerontol Geriatr Educ. 2016;38(4):471-481. doi:10.1080/0 2701960.2015 .1115983$.

32. Lipkin M. Shared decision making. JAMA Intern Med. 2013;173(13):1204 1205. doi:10.1001/jamainternmed.2013.6248.

33. Gonzalo JD, Heist BS, Duffy BL, et al. The art of bedside rounds: a multi-center qualitative study of strategies used by experienced bedside teachers. $J$ Gen Intern Med. 2013:28(3):412-420. doi:10.1007/s11606-012-2259-2.

34. Rosen P, Stenger E, Bochkoris M, Hannon MJ, Kwoh CK. Family-centered multidisciplinary rounds enhance the team approach in pediatrics. Pediat rics. 2009;123(4):e603-e608. doi:10.1542/peds.2008-2238.

35. Harrison R, Allen E. Teaching internal medicine residents in the new era. Inpatient attending with duty-hour regulations. J Gen Intern Med. 2006;21(5):447452. doi:10.1111/j.1525-1497.2006.00425.x.

36. Smith SK, Dixon A, Trevena L, Nutbeam D, McCaffery KJ. Exploring patient involvement in healthcare decision making across different education and functional health literacy groups. Soc Sci Med 1982. 2009;69(12):1805-1812. doi:10.1016/j.socscimed.2009.09.056 